\title{
HUBUNGAN ANTARA UMUR DAN KEBIASAAN MEROKOK DENGAN KELUHAN MUSCULOSKELETAL DISORDERS (MSDs) PADA PEKERJA ANGKAT ANGKUT UD MAJU MAKMUR KOTA SURABAYA
}

\author{
Ahmad Hanif \\ Keselamatan dan Kesehatan Kerja, Universitas Airlangga \\ Email: ahmadhanif602@gmail.com
}

\begin{abstract}
Musculoskeletal disorders (MSDs) complaints can be felt by all workers, including lifter workers. Complaints of MSDs are caused by damage to the joints, ligaments and tendons that can cause pain in the sceletal muscles. Individual factors that can cause MSDs complaints include age factors and smoking habits. Generally, MSDs complaints are felt at the age between 36-65 years and the level of complaints will continue to increase with age. Smoking habits can reduce lung capacity to consume oxygen, so that oxygen in the blood becomes low which causes fatigue and finally muscle pain arises. This research was conducted to analyze the correlation between age and smoking habits with MSDs complaints in lifters of UD Maju Makmur in Surabaya. This research was a descriptive observational study with a cross sectional approach. The population in this research were 20 lifters of UD Maju Makmur in Surabaya, and the sample is total of population. Age data and smoking habits were obtained from the questionnaire. Data on MSDs complaints were assessed using the Nordic Body Map (NBM) method. The data analysis was performed using the Spearman correlation test to see the strength of correlation between variabels. The results showed that there was a moderate relationship between age and MSDs complaints (correlation coefficient $=0.402$ ) and there was a moderate relationship between smoking habits and MSDs complaints (correlation coefficient $=$ 0.542). Conclusions in this study were the older age and the higher level of smoking category, there will be more complaints about MSDs. Suggestions for companies are to employ workers aged < 35 years in an effort to minimize MSDs complaints, and workers are advised to reduce or stop smoking early to avoid complaints of MSDs.
\end{abstract}

Keywords: Age, MSDs complaints, Smoking Habits

\begin{abstract}
ABSTRAK
Keluhan musculoskeletal disorders (MSDs) dapat dirasakan oleh semua pekerja, termasuk pekerja angkat angkut. Keluhan MSDs diakibatkan karena kerusakan pada sendi, ligamen dan tendon yang dapat menyebabkan rasa sakit pada otot skeletal. Faktor individu yang dapat menyebabkan keluhan MSDs diantaranya yaitu faktor umur dan kebiasaan merokok. Pada umumnya keluhan MSDs dirasakan pada umur antara 35-65 tahun dan tingkat keluhan akan terus meningkat sejalan dengan bertambahnya umur. Kebiasaan merokok dapat menurunkan kapasitas paru-paru untuk mengkonsumsi oksigen, sehingga oksigen dalam darah menjadi rendah yang menyebabkan kelelahan dan akhirnya timbul rasa nyeri otot. Penelitian ini dilakukan untuk menganalisis hubungan antara umur dan kebiasaan merokok dengan keluhan MSDs pada pekerja angkat angkut UD Maju Makmur
\end{abstract}


Kota Surabaya. Penelitian ini merupakan penelitian observasional deskriptif dengan rancangan penelitian menggunakan studi cross sectional. Populasi dalam penelitian ini adalah seluruh pekerja angkat angkut UD Maju Makmur Kota Surabaya sebanyak 20 orang, dan sampel dalam penelitian ini adalah total populasi. Data umur dan kebiasaan merokok diperoleh dari kuesioner. Data keluhan MSDs dinilai menggunakan metode Nordic Body Map (NBM). Data yang diperoleh dianalisis dengan uji korelasi spearman untuk melihat kekuatan hubungan antar variabel. Hasil penelitian menunjukkan bahwa ada hubungan sedang antara umur daengan keluhan MSDs (koefisien korelasi $=0,402$ ) dan ada hubungan sedang antara kebiasaan merokok dengan keluhan MSDs (koefisien korelasi $=0,542$ ). Simpulan dalam penelitian ini adalah semakin tua umur dan semakin tinggi tingkat kategori merokok pekerja, maka akan semakin mengalami keluhan MSDs. Saran bagi perusahaan yaitu memperkerjakan pekerja dengan umur $<35$ tahun sebagai upaya meminimalisir keluhan MSDs, serta pekerja disarankan untuk mengurangi atau berhenti merokok sejak dini agar terhindar dari keluhan MSDs.

Kata kunci: Kebiasaan merokok, Keluhan MSDs, Umur

\section{PENDAHULUAN}

Tingginya permintaan barang dan jasa akan meningkatkan kebutuhan jumlah tenaga kerja, salah satunya yaitu tenaga kerja sektor informal. Tenaga kerja sektor informal adalah pekerja yang bekerja tanpa relasi kerja, artinya mereka tidak ada perjanjian khusus yang mengatur tentang elemen kerja, gaji serta kekuasaan. Pekerja angkat angkut adalah pekerjaan mengangkat dan mengangkut barang atau material dari satu tempat ketempat lain. Pekerjaan tersebut biasanya menggunakan tubuh sebagai alat angkut seperti mengangkat, menjinjing, memanggul dan memikul.

Pekerjaan angkat angkut merupakan salah satu pekerjaan sektor informal yang harus mendapatkan perhatian. Salah satu dampak dari kurang maksimalnya upaya penerapan keselamatan dan kesehatan kerja (K3) adalah terjadinya Musculoskeletal Disorders (MSDs) pada pekerja. Persatuan Negara anggota Uni Eropa, 27 Negara diantaranya menyatakan bahwa di tahun 2004. MSDs adalah penyakit akibat kerja yang paling umum yaitu sebesar $59 \%$ dari semua penyakit akibat kerja. Berdasarkan data yang dikeluarkan oleh World Health Organization (WHO) pada tahun 2009 MSDs menyumbang lebih dari $10 \%$ yang menimbulkan kecacatan. ${ }^{1}$

Keluhan musculosketal disorders (MSDs) adalah keluhan yang dirasakan oleh seseorang pada bagian otot skeletal yang dimulai dari keluhan sangat rendah hingga keluhan sangat sakit. Apabila tubuh menerima beban statis secara berulang dan dalam waktu yang lama akan mengalami keluhan MSDs yang semakin meningkat. $^{2}$

Keluhan MSDs dapat dirasakan pada seluruh bagian otot skeletal, tergantung pada karakteristik gerakan fisik dan ergonominya. Faktor-faktor penyebab keluhan MSDs diantaranya adalah sikap kerja tidak alamiah, aktivitas berulang, peregangan otot yang berlebihan, faktor penyebab sekunder (getaran, 
tekanan dan mikroklimat), faktor kombinasi dan faktor individu (umur, kebiasaan merokok, jenis kelamin, ukuran tubuh, kesegaran jasmani dan kekuatan fisik). ${ }^{2}$

Faktor individu yang dapat menyebabkan keluhan MSDs diantaranya yaitu faktor umur dan kebiasaan merokok. Faktor umur adalah salah satu faktor dari individu yang memengaruhi keluhan MSDs. Keluhan MSDs biasanya dirasakan pada umur 35-65 tahun. Keluhan pertama umumya dirasakan pada umur 35 tahun dan akan terus meningkat seiring dengan bertambahnya umur. $^{2}$ Kebiasaan merokok juga salah satu faktor individu yang dapat memengaruhi keluhan MSDs. Hasil studi yang dilakukan oleh Boshuizen menyatakan bahwa ada hubungan yang signifikan antara kebiasaan merokok dengan keluhan otot pinggang pada pekerjaan yang memerlukan pengerahan otot. ${ }^{2,3}$

Data yang diperoleh dari Departemen Kesehatan RI tahun 2005 tentang permasalahan kesehatan yang ada di Indonesi menjelaskan bahwa terdapat sekitar $40,5 \%$ penyakit yang diderita pekerja berhubungan dengan pekerjaannya. Hasil studi di Indonesia mengenai gangguan kesehatan yang dialami oleh pekerja di 12 kabupaten/kota yang dilakukan pada 9.482 pekerja diperoleh hasil bahwa penyakit muskuloskeletal sebesar 16\%, kardiovaskuler sebesar $8 \%$, gangguan saraf sebesar 6\%, gangguan pernafasan sebesar 3\% dan gangguan THT sebesar $1,5 \% .^{3}$
Hasil penelitian oleh Soleha menyatakan bahwa ada hubungan antara umur dengan keluhan MSDs pada Operator Plant PT " $\mathrm{X}$ ". 4 Hasil studi yang dilakukan oleh Rahman menyatakan bahwa ada hubungan antara kebiasaan merokok dengan keluhan MSDs, dimana responden dengan kebiasaan merokok akan lebih banyak mengalami keluhan MSDs daripada responden yang tidak merokok. ${ }^{5}$

Berdasarkan hasil dari beberapa penelitian yang telah dilakukan tersebut di atas, dapat diketahui bahwa umur dan kebiasaan merokok dapat memberikan dampak buruk bagi para pekerja yaitu keluhan MSDs. Pekerjaan angkat angkut di UD Maju Makmur Kota Surabaya masih dilakukan secara manual dan lebih mengandalkan tenaga manusia. Kondisi tersebut sangat berpotensi menimbulkan permasalahan kesehatan yaitu keluhan MSDs. Hasil studi pendahuluan yang telah dilakukan sebelumnya dengan bertanya langsung dan observasi pada beberapa pekerja menunjukkan adanya keluhan MSDs seperti nyeri pada bagian punggung, tangan, dan leher dari para pekerja. Belum adanya penelitian dan intervensi perusahaan atas munculnya berbagai kasus keluhan MSDs dan permasalahan lain terkait dengan keluhan MSDs pada pekerjaan tersebut, maka penulis ingin meneliti lebih dalam tentang hubungan antara umur dan kebiasaan merokok dengan keluhan MSDs pada pekerja angkat angkut di UD Maju Makmur Kota Surabaya. 


\section{METODE PENELITIAN}

Penelitian ini merupakan penelitian observasional deskriptif dengan metode cross sectional. Total populasi dalam penelitian ini adalah seluruh karyawan bagian gudang yaitu pekerja angkat angkut UD Maju Makmur Kota Surabaya sebanyak 20 pekerja dan sampel dalam penelitian ini menggunakan total populasi. Penlitian ini dilakukan di UD Maju Makmur yang terletak di Jl. Margomulyo Pergudangan Angtropolis 46 Blok H-14/15 Surabaya. Waktu pengambilan data dilaksanakan pada bulan November 2018 dan pengolahan data pada bulan November-Desember 2018. Variabel bebas dalam penelitian ini adalah umur dan kebiasaan merokok, kemudian variabel terikatnya adalah keluhan MSDs.

Instrumen yang digunakan yaitu kuesioner, untuk mengetahui data umur dan kebiasaan merokok. Umur dikategorikan menjadi dua kategori yaitu $<35$ tahun dan $\geq 35$ tahun. $^{3}$ Kebiasaan merokok dikategorikan menurut Indeks Brinkman yaitu tidak merokok, perokok ringan, perokok sedang, dan perokok berat, serta pengisian lembar checklist Nordic Body Map (NBM) untuk menilai tingkat keluhan MSDs yang dikategori dari tingkat keluhan MSDs rendah, sedang, tinggi, dan sangat tinggi. Pengisian kuesioner dilakukan pada saat istirahat agar tidak mengganggu pekerjaan di perusahaan. Data sekunder diperoleh dari data UD Maju Makmur Kota Surabaya yang meliputi gambaran umum dan manajemen perusahaan.
Data tersebut kemudian diolah dalam beberapa tahapan yaitu editing data, coding data, entry data, cleaning dan tabulating data. Hasil pengumpulan data dianalisis menggunakan uji korelasi spearman untuk menganalisis hubungan antara variabel penelitian.

\section{HASIL DAN PEMBAHASAN}

\section{Hasil}

\section{Karakteristik Pekerja Berdasarkan Umur}

Berdasarkan hasil kuesioner pada pekerja angkat angkut UD Maju Makmur Kota Surabaya diperoleh umur terendah 26 tahun dan umur tertinggi 53 tahun dengan rata-rata umur 38 tahun. Pada penelitian ini, umur dikelompokkan menjadi dua kategori yang dapat dilihat pada Tabel 1 sebagai berikut.

Tabel 1. Karakteristik umur pekerja angkat angkut UD Maju Makmur Kota Surabaya

\begin{tabular}{lll}
\hline $\begin{array}{l}\text { Umur } \\
\text { (tahun) }\end{array}$ & $\begin{array}{l}\text { Frekuensi } \\
(\mathrm{n})\end{array}$ & $\begin{array}{l}\text { Persentase } \\
(\%)\end{array}$ \\
\hline$<35$ & 9 & 45,00 \\
$\geq 35$ & 11 & 55,00 \\
\hline Total & 20 & 100,00 \\
\hline
\end{tabular}

Dari Tabel 1 diketahui bahwa 55\% pekerja angkat angkut UD Maju Makmur Kota Surabaya masuk kelompok umur $\geq 35$ tahun.

\section{Karakteristik Pekerja Berdasarkan Kebiasaan Merokok}

Kebiasaan merokok diklasifikasikan menggunakan Indeks Brinkman (IB) = Jumlah rata-rata rokok perhari (batang) $\times$ Lama 
merokok (tahun). Pengklasifikasian kebiasaan merokok dapat dilihat pada Tabel. 2 berikut:

Tabel 2. Klasifikasi kebiasaan merokok

\begin{tabular}{ll}
\hline Indeks Brinkman & Klasifikasi \\
\hline $0-199$ & Perokok ringan \\
$200-599$ & Perokok sedang \\
\hline$\geq 600$ & Perokok berat \\
\hline
\end{tabular}

Sumber: Indeks Brinkman

Hasil perhitungan dengan Indeks Brinkman menunjukkan nilai terendah 120 dan nilai tertinggi 180 dengan rata-rata 210. Dari hasil penelitian juga terdapat dua pekerja yang tidak merokok. Hasil penelitian mengenai kebiasaan merokok dapat sebagai berikut:

Tabel 3. Karakteristik kebiasaan meroko pekerja angkat angkut UD Maju Makmur Kota Surabaya

\begin{tabular}{lrr}
\hline Kebiasaan merokok & $\begin{array}{l}\text { Frekuensi } \\
(\mathrm{n})\end{array}$ & \multicolumn{2}{l}{$\begin{array}{l}\text { Persentase } \\
(\%)\end{array}$} \\
\hline Tidak merokok & 2 & 10,00 \\
Perokok ringan & 12 & 60,00 \\
Perokok sedang & 6 & 30,00 \\
\hline Total & 20 & 100,00 \\
\hline
\end{tabular}

Dari Tabel 3 dapat diketahui bahwa $60 \%$ pekerja angkat angkut UD Maju Makmur Kota Surabaya termasuk kelompok perokok ringan.

\section{Tingkat Keluhan MSDs Pekerja}

Penentuan keluhan MSDs dalam penelitian ini menggunakan metode Nordic Body Map (NBM) dengan cara pengisian lembar checklist yaitu berupa peta tubuh (body map) yang memiliki 28 bagian otot skeletal yang dimulai dari anggota tubuh bagian atas yaitu otot leher sampai dengan bagian paling bawah yaitu otot pada kaki. Melalui lembar checklist NBM tersebut dapat diketahui bagian otot yang mengalami gangguan kenyerian atau keluhan dari tingkat rendah (tidak ada keluhan/sakit) sampai dengan keluhan tingkat tinggi (keluhan sangat sakit) dengan desain penilaian skoring. Setelah itu, menjumlahkan skor sehingga didapatkan skor akhir NBM untuk menentukan kategori tingkat keluhan MSDs yaitu keluhan rendah, sedang, tinggi dan sangat tinggi. ${ }^{2}$

Berdasarkan hasil penilaian yang dilakukan, skor akhir NBM terendah 48 dengan kategori rendah. Skor akhir NBM tertinggi 80 dengan kategori tinggi. Rata-rata skor akhir NBM sebesar 63. Hasil penilaian tingkat keluhan MSDs pada pekerja angkat angkut UD Maju Makmur Kota Surabaya dengan metode NBM diperoleh data sebagai berikut:

Tabel 4. Karakteristik tingkat keluhan MSDs pekerja angkat angkut UD Maju Makmur Kota Suabaya

\begin{tabular}{lrr}
\hline $\begin{array}{l}\text { Tingkat keluhan } \\
\text { MSDs }\end{array}$ & $\begin{array}{l}\text { Frekuensi } \\
(\mathrm{n})\end{array}$ & $\begin{array}{l}\text { Persentase } \\
(\%)\end{array}$ \\
\hline Rendah & 3 & 15,00 \\
Sedang & 13 & 65,00 \\
Tinggi & 4 & 20,00 \\
\hline Total & 20 & 100,00 \\
\hline
\end{tabular}

Dari Tabel 4 diketahui $65 \%$ pekerja angkat angkut UD Maju Makmur Kota Surabaya termasuk dalam tingkat keluhan MSDs sedang. 


\section{Hubungan Umur dengan Keluhan MSDs}

Hasil tabulasi silang keterkaitan antara umur dengan keluhan MSDs pada para pekerja angkat angkut UD Maju Makmur Kota Surabaya secara detail dapat dilihat pada Tabel 5 berikut ini:

Tabel 5. Tabulasi silang umur dengan keluhan MSDs pekerja angkat angkut UD Maju Makmur Kota Surabaya

\begin{tabular}{|c|c|c|c|c|c|c|c|c|}
\hline \multirow{3}{*}{ Umur } & \multicolumn{6}{|c|}{ Tingkat keluhan MSDs } & \multirow{2}{*}{\multicolumn{2}{|c|}{ Total }} \\
\hline & \multicolumn{2}{|c|}{ Rendah } & \multicolumn{2}{|c|}{ Sedang } & \multicolumn{2}{|c|}{ Tinggi } & & \\
\hline & $\mathrm{n}$ & $\%$ & $\mathrm{n}$ & $\%$ & $\mathrm{n}$ & $\%$ & $\mathrm{n}$ & $\%$ \\
\hline$<35$ tahun & 2 & 22,20 & 7 & 77,80 & 0 & 0,00 & 9 & 100,00 \\
\hline$\geq 35$ tahun & 1 & 9,10 & 6 & 54,50 & 4 & 36,40 & 11 & 100,00 \\
\hline Total & 3 & 15,00 & 13 & 65,00 & 4 & 20,00 & 20 & 100,00 \\
\hline & & & Koefis & korelas & 422 & & & \\
\hline
\end{tabular}

Dari Tabel 5 dapat diketahui bahwa hasil tabulasi silang menunjukkan bahwa $77,8 \%$ pekerja dalam kategori umur <35 tahun mengalami keluhan MSDs tingkat sedang. Kemudian 54,5\% pekerja kategori umur $\geq 35$ tahun mengalami keluhan MSDs tingkat sedang. Hasil uji statistik menunjukkan bahwa umur dengan keluhan MSDs memiliki hubungan yang positif (koefisien korelasi=0,422). Artinya semakin tua umur, maka akan semakin mengalami keluhan MSDs. Berdasarkan nilai koefisien korelasi, dapat disimpulkan bahwa hubungan antara umur dengan keluhan MSDs termasuk kategori sedang. ${ }^{6}$

Hasil penelitian tersebut berbeda dengan hasil studi yang dilakukan oleh Riihimaki dalam Tarwaka, yang menjelaskan bahwa umur mempunyai hubungan yang kuat dengan keluhan MSDs, terutama untuk otot leher dan bahu. ${ }^{2}$ Perbedaan tersebut terjadi karena faktor umur merupakan salah satu dari beberapa faktor individu yang dapat menyebabkan keluhan MSDs. Artinya keluhan MSDs tidak serta merta di pengaruhi oleh umur saja. Keluhan MSDs bisa di pengaruhi oleh beberapa faktor individu lain diantaranya yaitu kebiasaan merokok, ukuran tubuh, kesegaran jasmani dan kekuatan fisik. $^{2}$

Hasil penelitian ini juga menunjukkan bahwa 77,8\% pekerja dengan umur $<35$ tahun pun sudah merasakan tingkat keluhan MSDs tingkat sedang. Artinya dalam penelitian ini, umur bukanlah faktor individu yang dominan memengaruhi keluhan MSDs. Hal ini berbanding terbalik dengan teori yang dikemukakan oleh Tarwaka yang menyatakan bahwa keluhan MSDs pada umumnya dirasakan pada umur 35-65 tahun. Keluhan pertama biasanya dirasakan pada umur 35 tahun dan tingkat keluhan akan terus meningkat sejalan dengan bertambahnya umur. Hal tersebut dikarenakan pada umur setengah baya, kekuatan 
dan ketahanan otot mulai menurun sehingga risiko terjadinya keluhan otot meningkat. ${ }^{2}$

Hasil penelitian lain yang menunjukkan adanya hubungan antara umur dengan keluhan MSDs dilakukan oleh Soleha pada Operator Plant PT "X" yang menunjukkan adanya hubungan antara umur dengan terjadinya keluhan MSDs ${ }^{4}$. Prevalensi keluhan MSDs akan meningkat seiring dengan bertambahnya umur yang menyebabkan penurunan kapasitas fisik yang akan diikuti dengan penurunan VO2 max sehingga akan menurunkan kapasitas kerja. Hal ini disebabkan karena perubahan biologis, yaitu pada umur paruh baya kekuatan dan ketahanan otot mulai menurun karena proses penuaan. ${ }^{7}$
Keluhan MSDs yang ditimbulkan akibat karakteristik umur dapat dikurangi dengan meningkatkan kebugaran jasmani dan kekuatan fisik pekerja yaitu menjaga pola makan, olahraga dan istirahat cukup. Perusahaan dapat mengurangi berat beban yang diangkut khusus pekerja yang berumur lebih dari 35 tahun.

\section{Hubungan antara Kebiasaan Merokok dengan Keluhan MSDs}

Hasil tabulasi silang antara kebiasaan merokok dengan keluhan MSDs pada pekerja angkat angkut UD Maju Makmur Kota Surabaya dapat dilihat pada Tabel 6 berikut:

Tabel 6. Tabulasi silang kebiasaan merokok dengan keluhan MSDs pekerja angkat angkut UD Maju Makmur Kota Suabaya

\begin{tabular}{|c|c|c|c|c|c|c|c|c|}
\hline \multirow{3}{*}{ Kebiasaan merokok } & \multicolumn{6}{|c|}{ Tingkat keluhan MSDs } & \multirow{2}{*}{\multicolumn{2}{|c|}{ Total }} \\
\hline & \multicolumn{2}{|c|}{ Rendah } & \multicolumn{2}{|c|}{ Sedang } & \multicolumn{2}{|c|}{ Tinggi } & & \\
\hline & $\mathrm{n}$ & $\%$ & $\mathrm{n}$ & $\%$ & $\mathrm{n}$ & $\%$ & $\mathrm{n}$ & $\%$ \\
\hline Tidak merokok & 1 & 50,00 & 1 & 50,00 & 0 & 0,00 & 2 & 100,00 \\
\hline Ringan & 2 & 16,70 & 9 & 75,00 & 1 & 8,30 & 12 & 100,00 \\
\hline Sedang & 0 & 0,00 & 3 & 50,00 & 3 & 50,00 & 6 & 100,00 \\
\hline Total & 3 & 15,00 & 13 & 65,00 & 4 & 20,00 & 20 & 100,00 \\
\hline & & Koefi & n kor & $i=0,5$ & & & & \\
\hline
\end{tabular}

Dari Tabel 6 dapat diketahui bahwa hasil tabulasi silang menunjukkan bahwa $75 \%$ pekerja memiliki kebiasaan merokok ringan mengalami tingkat keluhan MSDs kategori sedang. Kemudian dari kebiasaan merokok sedang diketahui bahwa masing-masing 50\% pekerja mengalami keluhan MSDs sedang dan tinggi. Hasil uji statistik menunjukkan bahwa kebiasaan merokok dengan keluhan MSDs memiliki hubungan yang positif (koefisien korelasi=0,542). Artinya semakin tinggi tingkat kategori merokok pekerja, maka akan semakin mengalami keluhan MSDs. Berdasarkan nilai koefisien korelasi, dapat disimpulkan bahwa 
hubungan antara kebiasaan merokok dengan keluhan MSDs termasuk kategori sedang. ${ }^{6}$

Hasil penelitian tersebut sesuai dengan penelitian Rahman yang menyatakan bahwa ada hubungan antara kebiasaan merokok dengan keluhan MSDs, dimana responden yang memiliki kebiasaan merokok, lebih banyak mengalami keluhan MSDs dibandingkan dengan responden yang tidak merokok. ${ }^{5}$

Hasil penelitian pada pekerja angkat angkut UD Maju Makmur Kota Surabaya menunjukkan ada hubungan antara kebiasaan merokok dengan keluhan MSDs. Hal tersebut terjadi karena kebiasaan merokok adalah salah satu dari beberapa faktor individu yang dapat memengaruhi keluhan MSDs. Sehingga kebiasaan merokok dalam penelitian ini tidak secara langsung dapat menyebabkan terjadinya keluhan MSDs karena bisa dipengaruhi oleh faktor lain yaitu umur, jenis kelamin, kesegaran jasmani, ukuran tubuh dan kekuatan fisik. ${ }^{2}$

Hasil penelitian lain menunjukkan bahwa orang yang memiliki kebiasaan merokok akan lebih berisiko menderita sakit punggung daripada yang bukan perokok. Hal ini disebabkan karena batuk akibat terlalu banyak merokok dapat menambah tekanan pada perut dan menyebabkan ketegangan pada tulang belakang atau punggung. ${ }^{8}$ Hasil studi Boshuizen dalam Tarwaka, menyatakan bahwa ada hubungan yang signifikan antara kebiasaan merokok dengan keluhan otot pinggang pada pekerjaan yang memerlukan pengerahan otot. ${ }^{2}$.
Hasil penelitian pada pekerja angkat angkut UD Maju Makmur Kota Surabaya menunjukkan bahwa kebiasaan merokok dapat memengaruhi keluhan MSDs, hal tersebut terjadi karena seseorang yang memiliki kebiasaan merokok dapat menurunkan kapasitas paru-paru, saat kapasitas paru-paru mengalami penurunan maka oksigen yang di konsumsi juga semakin sedikit, sehingga kesegaran tubuh juga akan mengalami penurunan. Penurun kesegaran jasmani tersebut diakibatkan karena pada saat seseorang melakukan pekerjaan yang menuntut pengerahan tenaga, maka akan mudah lelah karena rendahnya kandungan oksigen dalam darah yang menyebabkan pembakaran karbohidrat terhambat, sehingga terjadi tumpukan asam laktat yang akhirnya timbul rasa nyeri otot.

Keluhan MSDs yang ditimbulkan akibat dari kebiasaan merokok dapat dikurangi atau dicegah dengan cara mengurangi atau berhenti merokok sejak dini, serta meningkatkan kebugaran jasmani.

\section{SIMPULAN DAN SARAN}

\section{Simpulan}

Sebagian besar pekerja angkat angkut UD Maju Makmur Kota Surabaya berusia $\geq 35$ tahun dan dalam kelompok perokok ringan. Penilaian keluhan MSDs dengan metode Nordic Body Map (NBM), sebagian besar pekerja angkat angkut UD Maju Makmur Kota Surabaya mengalami tingkat keluhan MSDs sedang. Penelitian ini menunjukkan adanya hubungan 
tingkat sedang antara umur dan kebiasaan merokok dengan keluhan MSDs pada pekerja angkat angkut UD Maju Makmur Kota Surabaya.

\section{Saran}

Sebaiknya perusahaan memperkerjakan pekerja dengan umur $<35$ tahun sebagai upaya meminimalisir keluhan MSDs yang dihadapi pekerja, dimana seiring dengan bertambahnya umur kekuatan otot akan terus mengalami penurunan, serta pekerja disarankan untuk mengurangi atau berhenti merokok sejak dini dan meningkatkan kebugaran fisik agar terhindar dari keluhan MSDs.

\section{REFERENSI}

1. ILO. The Prevention of Occupational Disease. 2013. http://www.ilo.org/wcmsp5/ groups/public/@ed_protect/@protrav/@safe work/documents/publication/wcms_208226. pdf

2. Tarawaka. Ergonomi Industri: Dasar-Dasar Pengetahuan Ergonomi dan Aplikasi di Tempat Kerja. Surakarta: Harapan Press. 2013.

3. Departemen Kesehatan RI. Strategi Nasional Kesehatan Kerja di Indonesia. Jakarta: Direktorat Bina Kesehatan Kerja. 2005.
4. Sugiyono. Metode Penelitian Kuantitatif, Kualitatif, dan R\&D. Bandung: Alfabeta. 2011.

5. Soleha, S. Hubungan Faktor Risiko Ergonomi dengan Keluhan Musculoskeletal (MSDs) pada Operator Cant Plant PT. X Plant Ciracas Jakarta Timur Tahun 2009. Skripsi. Jakarta: Fakultas Kedokteran dan Ilmu Kesehatan UIN Syarif Hidayatullah. 2009. http://www.jikm.unsri.ac.id/index.php/ jikm/article/viewFile/463/pdf

6. Rahman, A. Analisis Postur Kerja dan Faktor yang Berhubungan dengan Keluhan Musculoskeletal Disorders (MSDs) pada Pekerja Beton Sektor Informal di Kelurahan Samata Kecamatan Somba Opu Kabupaten Gowa Tahun 2017. Skripsi. Makasar: FK UIN Alaudin. 2017.

7. Maijunidah, E. Faktor-fakto yang Memengaruhi Keluhan Musculoskeleatal Disorders (MSDs) pada Pekerja Assembling PT X Bogor Tahun 2010. Skripsi. Jakarta: Fakultas Kedokteran dan Ilmu Kesehatan UIN Syarif Hidayatullah. 2010. http://repository.uinjkt.ac.id/dspace/bitstrea m/123456789/2388/1/EMI\%20MAIJUNID AH-FKIK.pdf

8. Bernard, B. P. Musculoskeletal Disorders and Workplace Factors: A critical Review of Epidemiologic Evidance for Work Related Musculoskeletal Disorders of the Neck, Upper Extremity, and Low Back. 1997.

9. Chaffin. Elements of Ergonomics Programs A Primer Based On Workplace Evaluations of Musculoskeletal Disorders. US Departement of Health And Human Services NIOSH. Amerika Serikat. 2005. 